\title{
Surface investigation and catalytic activity of iron-modified $\mathrm{TiO}_{2}$
}

\author{
Somayeh Sohrabi ${ }^{1} \cdot$ Faranak Akhlaghian $^{1}$
}

Received: 23 September 2015/ Accepted: 2 November 2015/Published online: 23 November 2015

(C) The Author(s) 2015. This article is published with open access at Springerlink.com

\begin{abstract}
Iron-modified titanium dioxide nanostructured catalyst was synthesized by sol-gel method. Due to the important impacts of surface properties on the catalytic activity, the catalyst surface is investigated. To have a complete characterization of the catalyst, TEM, SEM, XPS, XRF, XRD, BET, and TGA-DTA techniques were used. XRF analysis reveals the iron loading of the synthesized catalyst as $\mathrm{Fe}_{2} \mathrm{O}_{3} / \mathrm{TiO}_{2}=0.21 \%$. XRD results imply that the catalyst is composed of anatase and rutile phases. The SEM image indicates the mesoporousity of the nanoparticles. Clusters are observable in the TEM images. The main objective of activity tests is focused upon the comparative evaluation of $\mathrm{H}_{2} \mathrm{O}_{2}$ addition and the application of air bubbling. Experimental results specified that the optimum amount for $\mathrm{H}_{2} \mathrm{O}_{2}$ dosage is $12.5 \mathrm{ml}$. Moreover, it has been observed that an increase in the aeration flow rate shows a positive effect on the degradation of phenol and the optimum aeration flow is $9 \mathrm{l} / \mathrm{min}$. Furthermore, it has been shown that the addition of copper as additive ion to phenol solution boosts the degradation of phenol; the highest phenol degradation efficiency after $120 \mathrm{~min}$ $(43.85 \%)$ was attained under this condition.
\end{abstract}

Keywords Surface characterization · Iron-modified titanium dioxide $\cdot$ Catalyst $\cdot$ Dopant

Somayeh Sohrabi

sohrabisomayeh@yahoo.com; s.sohrabi@eng.uok.ac.ir

1 Department of Chemical Engineering, Faculty of Engineering, University of Kurdistan, Sanandaj, Iran

\section{Background}

All solid materials interact with their surroundings through their surfaces. The characteristics of these interactions are defined by the physical properties and chemical composition of the surfaces. The surface chemistry affects important properties of the solid such as the corrosion rates, catalytic activity, adhesive properties, wettability, contact potential, and failure mechanisms. It has been proven that the catalytic activity of a catalyst depends not only on chemical components, but also on the particles dimension, morphology, and structural properties of the catalyst. Moreover, the catalyst preparation method has a great impact on the particle properties and the dispersion state of the active components. Different preparation methods such as incipient wetness impregnation, co-precipitation, hydrothermal synthesis, and sol-gel method are often used to obtain the catalysts with different physicochemical properties. The preparation method has a significant role in improving the activity of catalysts $[1-3] \cdot \mathrm{TiO}_{2}$, which is used in the decomposition of organics, is one of the most efficient photocatalysts that acts in the ambient conditions. Moreover, $\mathrm{TiO}_{2}$ is considerably available, inexpensive, non-toxic, and it is reputed for its high chemical stability [3]. $\mathrm{TiO}_{2}$ has various applications in fields of hydrogen production, antibacterial activity, air cleaning and water treatment processes, and it has been applied for the decomposition of a large number of organic pollutants. The application of $\mathrm{TiO}_{2}$ in degradation of pollutants is considered as a promising technique in the wastewater industry [4]. Loghman Karimi and Salar Zohoori synthesized $\mathrm{TiO}_{2} /$ $\mathrm{SrTiO}_{3}$ nanocomposite and evaluated its photocatalytic activity by the degradation of azo dyes. On the composite system, strontium titanate plays the role of electron acceptor to accelerate photodecomposition [5]. Numerous 
research projects have focused on the surface modification of $\mathrm{TiO}_{2}$, the most commonly employed modification method is loading nano-sized metals on $\mathrm{TiO}_{2}$ surface. Dopants are used to retard the fast charge recombination and enhance the interfacial charge transfer [6]. Metallic nanoparticles such as Pt [7], Pd [8], Au [9], Ag [10-14], Ru [15], and Fe [16-20] have been used to enhance the photocatalytic activity of $\mathrm{TiO}_{2}$ by decelerating the recombination behaviors. The photo-induced electrons migrate to the metal due to the relatively low Fermi level of metals, which make the photo-induced holes stable on the $\mathrm{TiO}_{2}$ surface and contributes to the charge separation [3, 21, 22]. Therefore, more $\mathrm{OH}$ radicals are generated as an enhanced redox reaction [4].

The following is a summary of research papers that are typically associated with the modification of $\mathrm{TiO}_{2}$ with $\mathrm{Fe}$. Oganisian et al. [23] studied the influence of $\mathrm{Fe}$ ions on the magnetic properties of $\mathrm{TiO}_{2}$. The magnetization as a function of temperature and applied magnetic field of $\mathrm{TiO}_{2}$ nanopowders doped with 1,5 and $10 \mathrm{~mol} \% \mathrm{Fe}$ and prepared by sol-gel method in two different ways has been measured in the wide temperature and magnetic field range. Except for the low Fe fraction samples, all compounds exhibit the paramagnetic behavior with the negative Curie temperature that suggests the antiferromagnetic ordering. The measurements showed that magnetic properties are more related to the nanopowders preparation method than to their grain size [23]. Hreniak et al. [24] investigated the optical properties of iron-modified titanium dioxide. Titanium dioxide nanoparticles with different amount of $\mathrm{Fe}$ were synthesized by a sol-gel method. The zeta potential analysis indicates that existence of iron changed the zeta potentials of titanium dioxide. Magnetic force microscopy study illustrates the ferromagnetic nature of observed particles. The SEM images confirm the nanostructure of the catalysts [24]. Ranjit and Viswanathan [25] showed that doping $\mathrm{TiO}_{2}$ with $\mathrm{Fe}$ (III) enhances its photocatalytic activity. They ascribed the improved photocatalytic activity of the iron-doped catalysts to the heterojunction formed between the $\mathrm{Fe} / \mathrm{TiO}_{2}$ and $\alpha-\mathrm{Fe}_{2} \mathrm{O}_{3}$ phases for the sol-gel-derived catalysts [25]. Liu et al. [26] prepared the Fe-doped $\mathrm{TiO}_{2}$ nanorod clusters and monodispersed nanoparticles by a modified hydrothermal and solvothermal method. The $\mathrm{Fe}^{3+}$ dopants in $\mathrm{TiO}_{2}$ lattices not only lead to the significantly extending of the optical responses from UV to visible region, but also diminish the recombination rates of the electrons and holes. The photocatalytic activities were evaluated by photocatalytic decomposition of formaldehyde in air under visible light illumination. Compared with $\mathrm{P} 25\left(\mathrm{TiO}_{2}\right)$ and $\mathrm{N}$-doped $\mathrm{TiO}_{2}$ nanoparticles, the $\mathrm{Fe}$-doped photocatalysts show high photocatalytic activities under visible light [26]. Naik and Parida [27] Prepared and characterized mesoporous
$\mathrm{Fe}_{x} \mathrm{Ti}_{1-x} \mathrm{O}_{2-y} \mathrm{~N}_{y}$ nanophotocatalyst (FeNT). They demonstrated that the presence of $\mathrm{Fe}$ ion facilitates the surface charge transfer and noted that the synergistic effect of iron and nitrogen greatly enhances the photocatalytic activity [27]. Barakat et al. [28] investigated $\mathrm{ZnO}-\mathrm{Fe}_{2} \mathrm{O}_{3}$ incorporated $\mathrm{TiO}_{2}$ nanofibers as a photocatalyst for water splitting under visible light radiation. The band gap energy of titanium oxide nanofibers was modified by $\mathrm{Fe}_{2} \mathrm{O}_{3}$ and $\mathrm{ZnO}$ incorporation to be used as effective photocatalysts in water splitting process under visible light radiation [28].

The main goal of this study is optimizing $\mathrm{H}_{2} \mathrm{O}_{2}$ dosage, air bubbling, temperature, and additive ions on the photocatalysis using iron-modified titanium dioxide. The other objective of this work is the study of the surface of the catalyst and our focus is on the surface composition, structure, and morphology of $\mathrm{Fe} / \mathrm{TiO}_{2}$. Sol-gel method was chosen because the stoichiometry of the proposed process is controllable and the powders, which are synthesized by this method, are highly pure and the required equipment is inexpensive.

\section{Methods}

\section{Material and method}

Titanium isopropoxide $(98 \%)$ and $\mathrm{Fe}\left(\mathrm{NO}_{3}\right)_{3} \cdot 9 \mathrm{H}_{2} \mathrm{O}$ (98\%) were used as the precursors for the titanium and iron, respectively. Moreover, ethanol (96\%), nitric acid $(65 \%), \mathrm{H}_{2} \mathrm{O}_{2}(30 \%)$ and phenol $(99 \%)$ were used in the experiments. All the materials were purchased from Merck Company. The materials were of analytical grade and were used without further purifications.

Following Yoldas method, titanium isopropoxide was added to double-distilled water. The molar ratio of titanium isopropoxide to water was 1:100. The mixture was stirred at a constant rate and heated until the temperature reached $85{ }^{\circ} \mathrm{C}$. Then nitric acid was added. The molar ratio of titanium isopropoxide to nitric acid was 1:0.07. Fe was added to the mixture through the solution, which is obtained by dissolving $\mathrm{Fe}\left(\mathrm{NO}_{3}\right)_{3} \cdot 9 \mathrm{H}_{2} \mathrm{O}$ in ethanol. The mixture was under reflux at $85{ }^{\circ} \mathrm{C}$ for $24 \mathrm{~h}$. The obtained gel was dried at $100{ }^{\circ} \mathrm{C}$ in an oven. Then, the calcination process had been taken place in a furnace at $600{ }^{\circ} \mathrm{C}$ for $2 \mathrm{~h}$ [29]. Finally, $\mathrm{Fe} / \mathrm{TiO}_{2}$ was crushed and sieved into 60-90 $\mu \mathrm{m}$.

\section{Characterization techniques}

Surface morphology of the catalyst was investigated by SEM of TSCAN company on $25.0 \mathrm{kV}$ acceleration voltage and TEM analyze was performed by transmission electron microscope of Zeiss company operated at acceleration 
Fig. 1 TEM images of images of iron-modified titanium dioxide
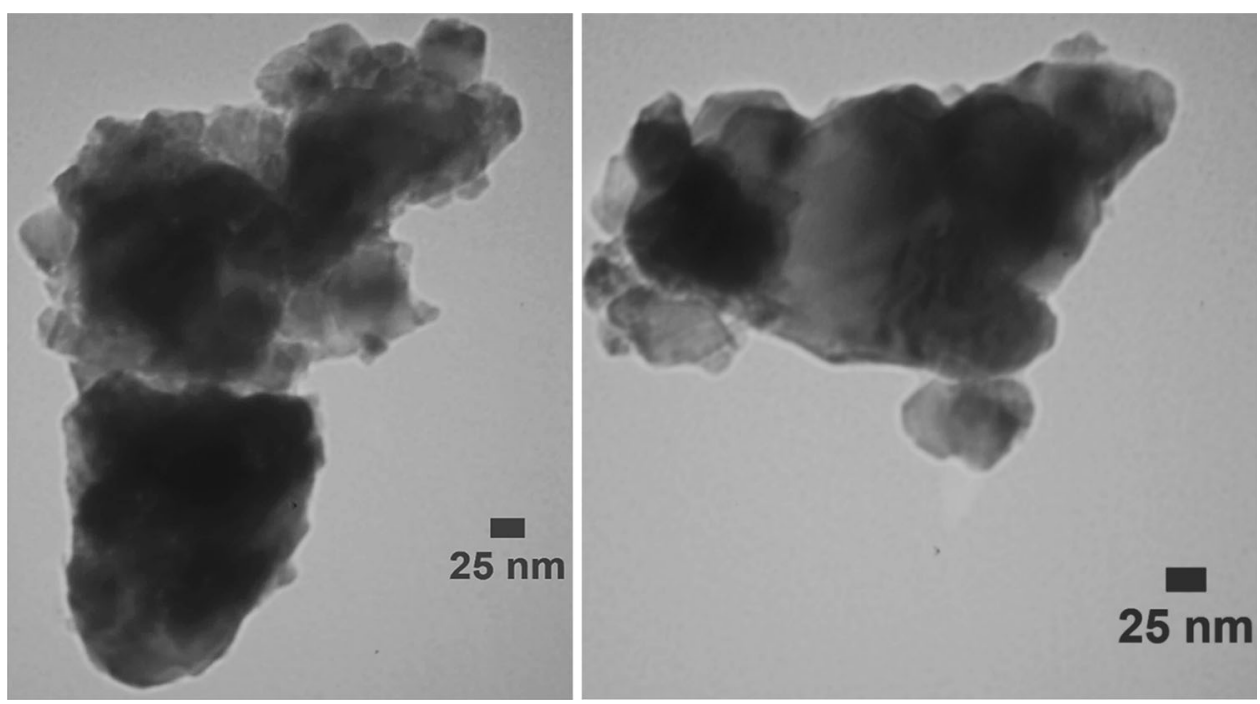

voltage of $80 \mathrm{kV}$. An important step in characterizing the surface chemistry of the specimen is to identify the elements present on the surface. To achieve this, we used X-ray photoelectron spectroscopy (XPS:TWIN ANODE XR3E2 X-RAY SOURCE SYSTEMS, X-RAY 8025-Bes$\mathrm{Tec})$ and recorded a survey spectrum over the region of 0-1200 eV that provided fairly strong peaks for all elements in the periodic table. The data were presented as a graph of intensity versus electron energy. Iron content of the catalyst was measured by SPECTRO X-labPro X-ray fluorescence (XRF) spectrometer. The XRD pattern was collected using X'Pert MPD diffractometer of the Philips company (the Netherlands) with $\mathrm{Cu} \mathrm{K} \alpha$ radiation at $40 \mathrm{kV}$ and $40 \mathrm{~mA}$ at a scan rate of $0.2 \%$ over $2 \theta$ range of $5^{\circ}-$ $80^{\circ}$. Specific surface area (BET) of the sample was measured using an ASAP Micrometrics 2011. The TGA-DTA analysis of the $\mathrm{Fe} / \mathrm{TiO}_{2}$ catalyst was carried out in a TGA analyzer ATA PT1000 model of the Linseis Company under static air atmosphere in the temperature range of $33.5-650{ }^{\circ} \mathrm{C}$.

\section{Results and discussions}

\section{Characterization}

TEM images of the catalyst are shown in Fig. 1. It can be observed that particles tend to agglomerate at dimensions near $250 \mathrm{~nm}$. The structure and morphology of the catalyst were investigated by Scanning Electron Microscopy. SEM image of the catalyst is depicted in Fig. 2. Porous structure of the catalyst is revealed in this nanoscale image.

Figure 3 shows the typical XPS survey scan of the Fe/ $\mathrm{TiO}_{2}$ sample. No iron could be detected in the surface of sample, which could be because of low concentration of

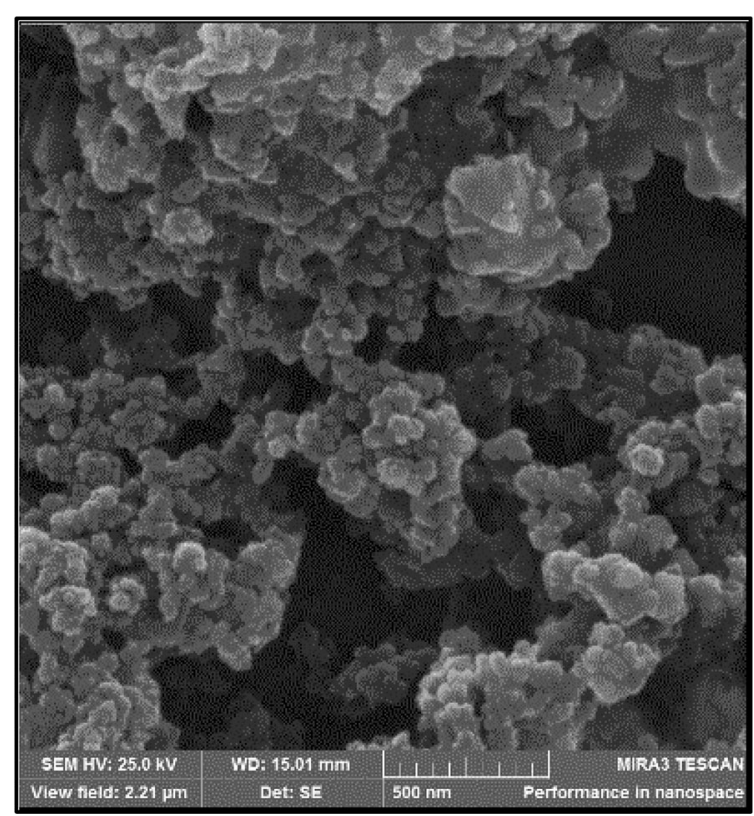

Fig. 2 SEM image of iron-modified titanium dioxide

iron being dopant. $\mathrm{TiO}_{2}$ rutile structure has open diffusion channels with a radius of $\sim 0.77 \AA$ that run parallel to the $c$-axis [30]. Since the radius of $\mathrm{Fe}^{3+}$ is $0.64 \AA$, which is smaller than both the $0.77 \AA$ channels in the porous structure of pure $\mathrm{TiO}_{2}$ and the radius of $\mathrm{Ti}^{4+}(0.68 \AA)$ [ 31 , $32]$, it is possible that $\mathrm{Fe}^{3+}$ diffuses along the $c$-axis and substitutes $\mathrm{Ti}^{4+}$ in the $\mathrm{TiO}_{2}$ lattice [31]. Figure 3a, b show the high-resolution XPS spectra of titanium and oxygen. From Fig. 3a, it is clear that there are four contributions to the $\mathrm{Ti} 2 p$ region: the $\mathrm{Ti}(2 p 3 / 2)$ and $\mathrm{Ti}(2 p 1 / 2)$ at binding energies of 458.8 and $464.4 \mathrm{eV}$, respectively. These values for binding energies are in agreement with the values relevant to $\mathrm{TiO}_{2}$, moreover, the difference between these two 


\section{XPS spectra of $\mathrm{Fe} / \mathrm{TiO}_{2}$}
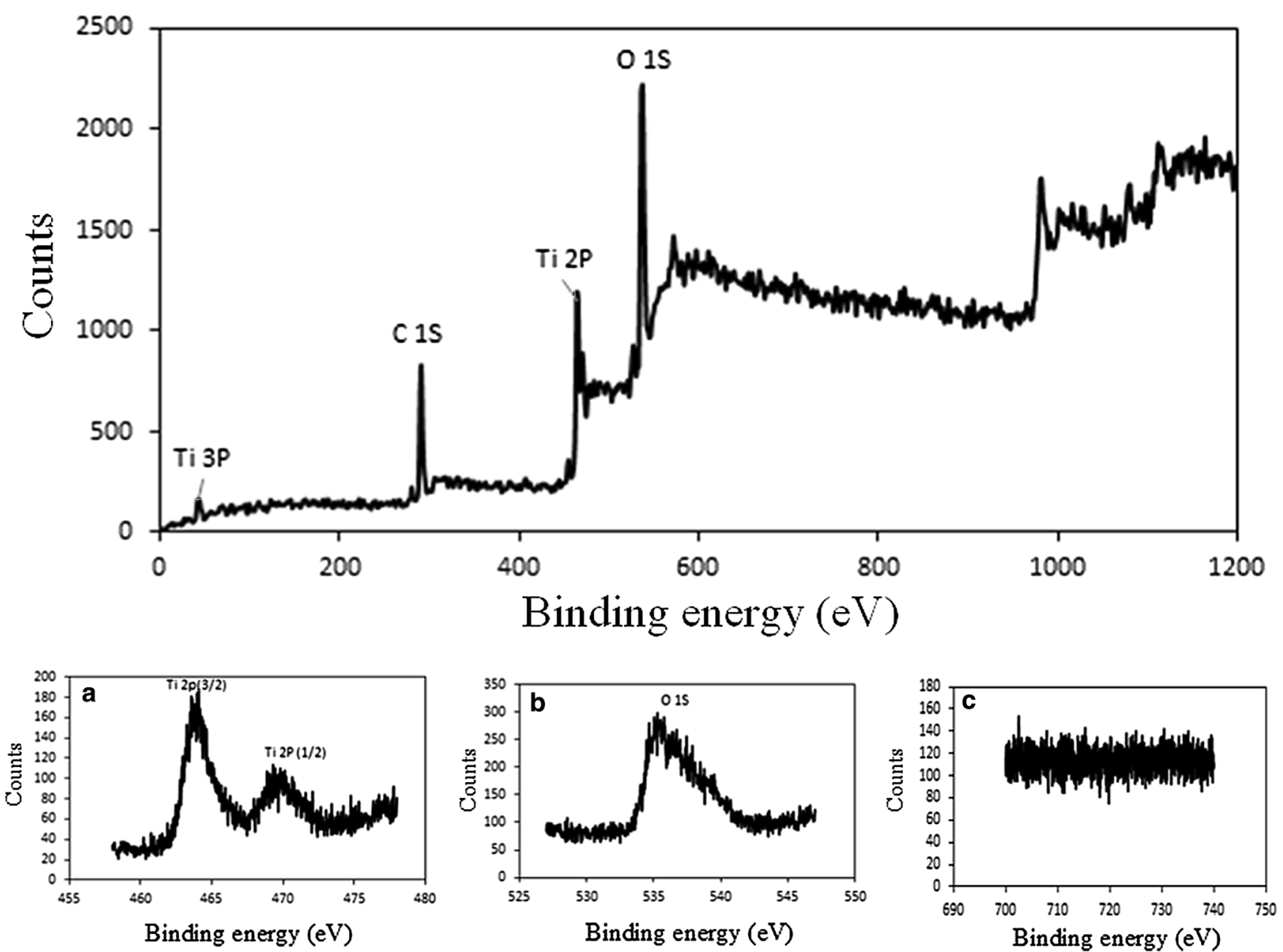

Fig. 3 XPS survey scan of the $\mathrm{Fe} / \mathrm{TiO}_{2}$ sample. a XPS spectra of titanium, b XPS spectra of oxygen, $\mathbf{c}$ XPS resolution spectrum of Fe

binding energies represents the standard binding energy for Ti element [33]. Upon substitution of $\mathrm{Ti}^{4+}$ with $\mathrm{Fe}^{3+}$, the number of electrons of the conduction band of $\mathrm{TiO}_{2}$ is increased, this bring about the migration of these electrons to iron which results in a decrease in the outer electron cloud density of $\mathrm{Ti}$ ions, and overall, It leads to the corresponding increase in generation of surface state of $\mathrm{Ti}^{3+}$. Hence, the existence of the $\mathrm{Ti}^{3+}$ means the presence of $\mathrm{Fe}^{3+}$. Existence of $\mathrm{Ti}^{3+}$ will retard the recombination of the $\mathrm{h}^{+}$and $\mathrm{e}^{-}$, which has a positive effect on the catalytic activity of $\mathrm{Fe} / \mathrm{TiO}_{2}$ [34, 35]. Figure 3b shows the corresponding spectra of oxygen with the following composition: The main contribution of oxygen in the $\mathrm{Fe} / \mathrm{TiO}_{2}$ is composed of $\mathrm{O}^{2-}(58.1 \%)$, which can be assigned to the oxygen bounded in the $\mathrm{TiO}_{2}$ lattice $(\mathrm{Ti}-\mathrm{O})$. Its peak is corresponded to binding energy of $530.10 \mathrm{eV}$. Moreover, $16.6 \%$ of the total oxygen is associated with $\mathrm{O}^{-}$which is indicated the presence of surface hydroxyl groups (Ti-OH) as chemisorbed water, The relevant peak is located around
$531.8 \mathrm{eV}$ and finally $25.3 \%$ is in the form of physically absorbed water, pertaining to the peak at $533.4 \mathrm{eV}[34,35]$. Figure $3 \mathrm{c}$ indicates that iron concentration is below the detection level of XPS. The enhanced activity of $\mathrm{Fe} / \mathrm{TiO}_{2}$ compared with $\mathrm{TiO}_{2}$ is experimentally shown in Fig. 4, which confirms that $\mathrm{Fe}^{3+}$ ions are absorbed on the $\mathrm{TiO}_{2}$ surface, acting as electron trapping centers. Thus, they increase the electron-hole pair separation efficiency and accordingly, superior activity of $\mathrm{Fe} / \mathrm{TiO}_{2}$ confirms the presence of iron in the surface of the photocatalyst.

The results of XRF analysis for the catalyst characterization are presented in Table 1 . Chemical composition of the synthesized catalyst reveals that it is consisted of $\mathrm{TiO}_{2}$ $(95.85 \%), \mathrm{Fe}_{2} \mathrm{O}_{3}(0.20 \%)$ and $\mathrm{Na}_{2} \mathrm{O}(0.42 \%), \mathrm{Al}_{2} \mathrm{O}_{3}$ $(0.69 \%), \mathrm{SiO}_{2}(2.84 \%)$ and the ratio of $\left(\mathrm{Fe}_{2} \mathrm{O}_{3} / \mathrm{TiO}_{2}\right)$ is $(0.2 \% / 95.85 \%=0.21 \%)$.

XRD pattern of the catalyst is shown in Fig. 5. Peaks at $32.0095^{\circ}, 42.1696^{\circ}$ and $64.0611^{\circ}$ are attributed to the rutile phase (JCPDS File no. 21-1276) and the peak at $29.5090^{\circ}$ 


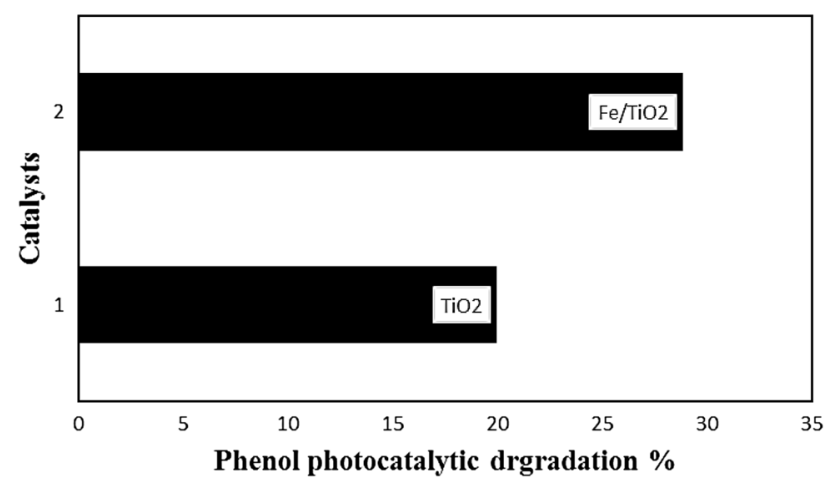

Fig. 4 The effect of Fe photocatalytic activity of the catalyst (Initial phenol concentration: $200 \mathrm{ppm}$, catalyst loading: $0.5 \mathrm{~g} / 1, \mathrm{H}_{2} \mathrm{O}_{2}$ : $12.5 \mathrm{ml}, 30 \mathrm{wt} \%$, reaction time: $120 \mathrm{~min}$, UV light intensity of $757.38 \mathrm{~mW} / \mathrm{cm}^{2}$ )

Table 1 Chemical composition of the catalyst

\begin{tabular}{llll}
\hline $\mathrm{Z}$ & Symbol & Element & Concentration (\%) \\
\hline 22 & $\mathrm{TiO}_{2}$ & Titanium & 95.85 \\
26 & $\mathrm{Fe}_{2} \mathrm{O}_{3}$ & Iron & 0.20 \\
11 & $\mathrm{Na}_{2} \mathrm{O}$ & Sodium & 0.42 \\
13 & $\mathrm{Al}_{2} \mathrm{O}_{3}$ & Aluminum & 0.69 \\
14 & $\mathrm{SiO}_{2}$ & Silicon & 2.84 \\
\hline
\end{tabular}

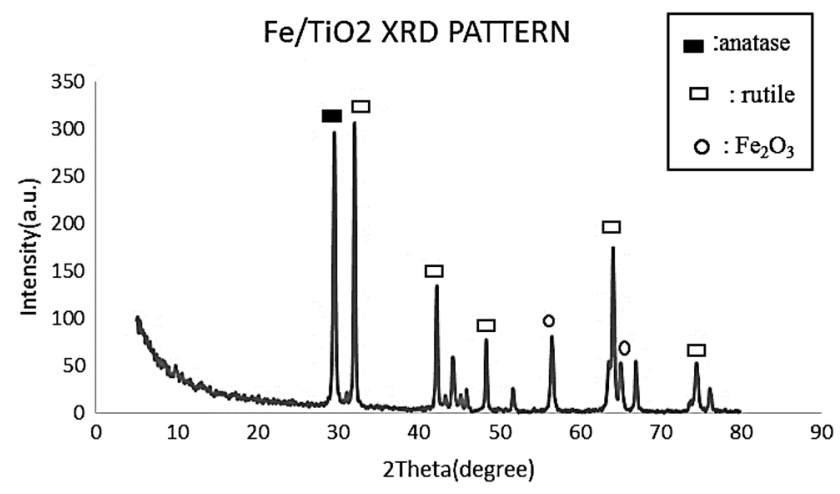

Fig. 5 XRD pattern of $\mathrm{Fe} / \mathrm{TiO} 2$

is attributed to the anatase phase (ICPDS File no. 21-1272). These results imply that both rutile and anatase phases exist in the catalyst. In addition to the peaks belonging to rutile and anatase phases other peaks are also recognized which correspond to iron oxides of $\mathrm{Fe}_{2} \mathrm{O}_{3}$ (JCPDS File no. 39-1346). It confirms the existence of iron as dopant in the sample and proves that iron is in its oxide form.

BET model, which was developed by Brunauer, Emmet and Teller is applied for measuring the surface of the catalyst. Based on the IUPAC classification, porous structures are categorized based on their pore sizes, micro pores (pores with diameters less than $2 \mathrm{~nm}$ ), mesopores (pores with $2-50 \mathrm{~nm}$ diameter), and macropores (pores with diameters greater than $50 \mathrm{~nm}$ ) [36]. Since the average pore diameter of $\mathrm{Fe} / \mathrm{TiO}_{2}$ (4 V/A by BET) is $13.9838 \mathrm{~nm}$, the catalyst is considered mesoporous, according to IUPAC classification and specific surface area of the catalyst is $5.1268 \mathrm{~m}^{2} / \mathrm{g}$. Pore size distribution is multimodal and the decreased prevalence of the pores with increased pore size is evident in Fig. 6.

Figure 7 shows the thermal gravimetric analysis (TGA) and differential thermal analysis (DTA) of $\mathrm{Fe} / \mathrm{TiO}_{2}$ catalyst. In TGA curve, three regions with different slopes are recognized. These regions are 33.5-200.6, 200.6-416.5, and $416.5-650{ }^{\circ} \mathrm{C}$, respectively. In the first region, weight loss is attributed to the vaporization of water and the degradation of volatile organic materials. In the second region, 200.6-416.5 ${ }^{\circ} \mathrm{C}$, decomposition of the organic materials with strong bound has occurred. Weight loss in the third region, $416.5-600{ }^{\circ} \mathrm{C}$, is negligible and insignificant. In DTA curve, an endothermic broad peak around $100{ }^{\circ} \mathrm{C}$ is observed which is attributed to the vaporization of water. The following two exothermic peaks around $200{ }^{\circ} \mathrm{C}$ are attributed to the combustion of organics. The broad exothermic peak with onset of $400{ }^{\circ} \mathrm{C}$ is representative of the crystallization process. It is notable that below this temperature, the material is amorphous; at $400{ }^{\circ} \mathrm{C}$ crystallization begins with the formation of anatase followed by phase transformation from anatase to rutile. The results show excellent agreement with the work of Mesgari et al. [37].

\section{Activity tests}

The photocatalytic activity of Fe-doped $\mathrm{TiO}_{2}$ nanoparticles was examined by studying the degradation of phenol. A specified amount of the synthesized catalyst $(0.5 \mathrm{~g} / \mathrm{l})$ was added to the phenol solution ( $200 \mathrm{ppm}, 200 \mathrm{ml}$ ), which was selected as the synthetic wastewater. The amount of Fe-loading of $\mathrm{Fe} / \mathrm{TiO}_{2}$ catalyst, initial phenol concentration, and catalyst dosage were investigated and optimized in our previous work [38]. Hydrogen peroxide $\left(\mathrm{H}_{2} \mathrm{O}_{2}\right.$ : $30 \mathrm{wt} \%$ ) was added to the solution as an oxidizing agent. The mixture was stirred at a constant rate and illuminated by the UV lamp (with light intensity of $757.38\left(\mathrm{~mW} / \mathrm{cm}^{2}\right)$ which was fixed $19.5 \mathrm{~cm}$ above the batch reactor (Pyrex vessel capacity: 21 ). In this work, air bubbling is carried out by two parallel air pumps. One RS Electrical (model: RS-610) with the maximum flow of $3.51 / \mathrm{min}$ and the other is HAILEA (model: ACO-5505), with maximum flow is $5.5 \mathrm{l} / \mathrm{min}$. The setup was shielded by aluminum foil during the reaction time to prevent the interference with outside light. After $2 \mathrm{~h}$ of reaction, the mixture was centrifuged and the absorbance of the supernatant solution was measured at $270 \mathrm{~nm}$ using a Specord $210 \mathrm{UV}$ spectrometer. The experiments were repeated for the blank. All the 
Fig. 6 Pore size distribution according to $\mathrm{BJH}$ adsorption of $\mathrm{Fe} / \mathrm{TiO} 2$
Fig. 7 TGA-DTA curve of the $\mathrm{Fe} / \mathrm{TiO} 2$

\section{BJH Adsorption Cumulative Pore Volume}

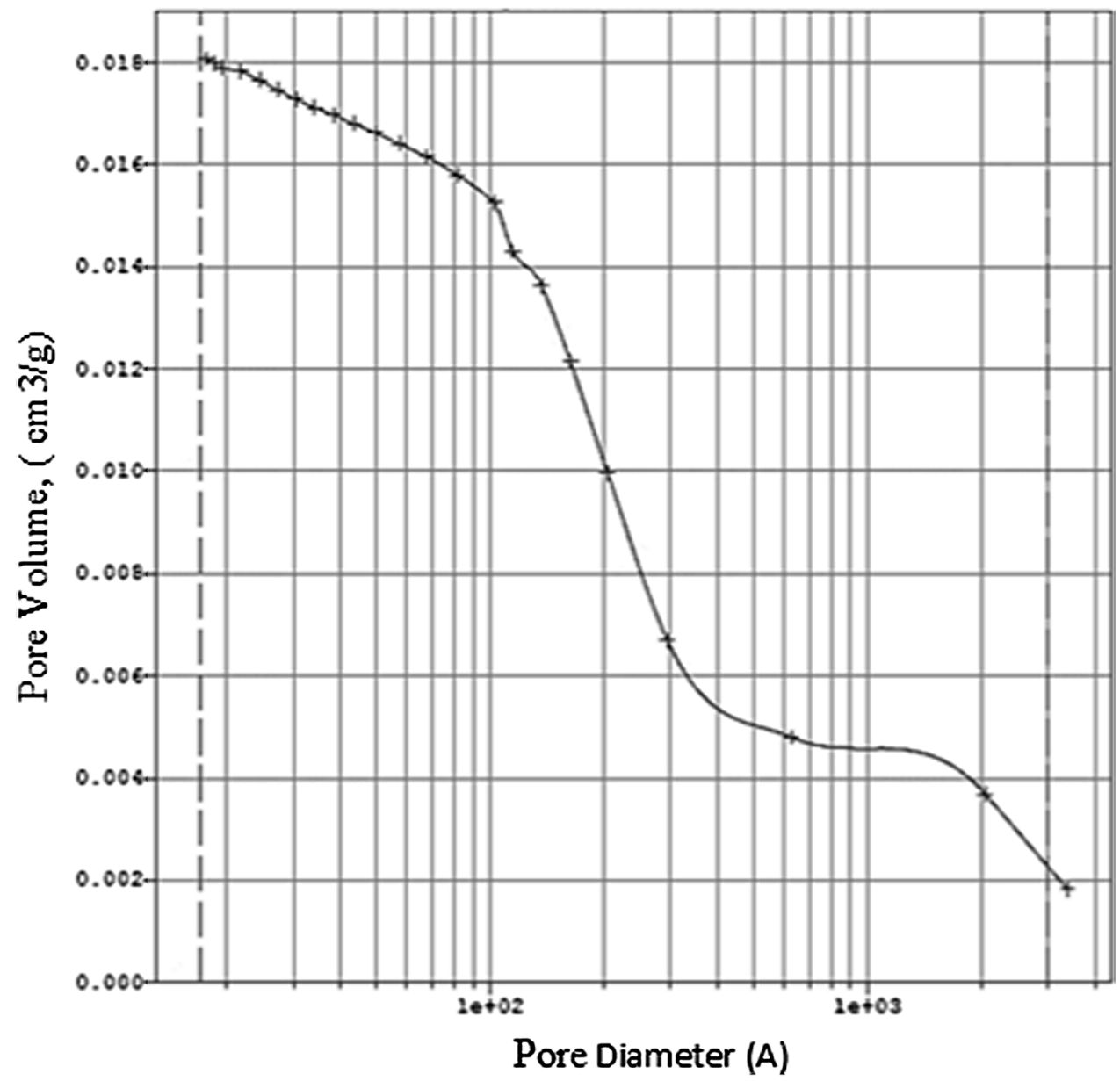

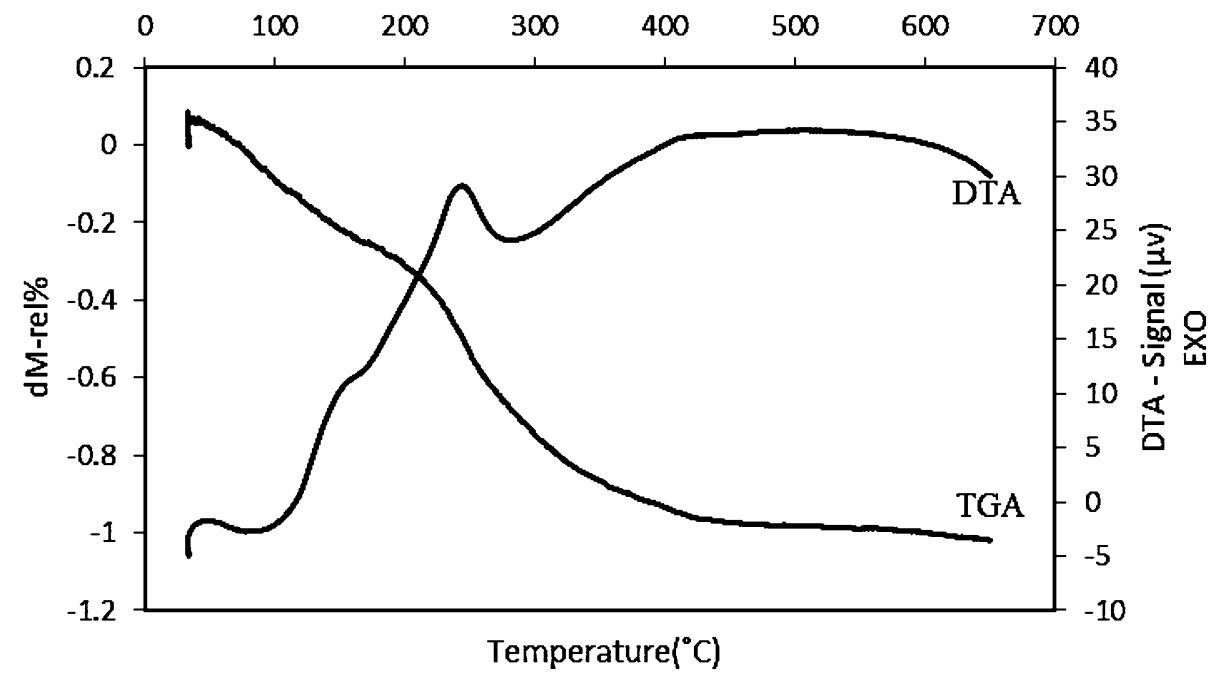

conditions in the blank were the same as the sample, but it had no catalyst. The concentration of phenol in the solution was measured using Beer-Lambert law and photo degradation of phenol was calculated using following equation:
Degradation $\%=100 \times\left[\left(\operatorname{Ad}_{0}-\mathrm{Ad}\right) / \operatorname{Ad}_{0}\right]$

where $\operatorname{Ad}_{0}$ and $\mathrm{Ad}$ are the absorbance of blank and sample, respectively [38]. 
$\mathrm{H}_{2} \mathrm{O}_{2}$

Adding proper amount of electron acceptor results in preventing the electron-hole recombination and increasing the number of hydroxyl radicals and other oxidizing agents. Optimization of $\mathrm{H}_{2} \mathrm{O}_{2}$ dosage is a fundamental factor in the photocatalytic degradation of phenol. Hydroxyl generation can be executed through three routes, the first route is $\mathrm{H}_{2} \mathrm{O}_{2}$ photo-dissociation, the second route is the reaction between $\mathrm{H}_{2} \mathrm{O}_{2}$ photogenerated electrons on $\mathrm{TiO}_{2}$ surface, and the third one is the reaction between $\mathrm{H}_{2} \mathrm{O}_{2}$ and peroxyl ion that is produced from the reaction of dissolved $\mathrm{O}_{2}$ and electrons of conduction band [39]. An experiment was conducted with different dosages of $\mathrm{H}_{2} \mathrm{O}_{2}$ and the results are given in Fig. 8. It has been shown that at low $\mathrm{H}_{2} \mathrm{O}_{2}$ concentrations, the produced $\cdot \mathrm{OH}$ radicals are not sufficient for phenol photocatalytic degradation. However, high concentrations of hydrogen peroxide will lead to a decrease in phenol degradation, since $\cdot \mathrm{OH}$ radicals react with the excess $\mathrm{H}_{2} \mathrm{O}_{2}$. This reaction consumes hydroxyl radicals and competes with phenol oxidation. According to Fig. 8, increasing the $\mathrm{H}_{2} \mathrm{O}_{2}$ dosage up to $12.5 \mathrm{ml}$ enhances the activity of $\mathrm{Fe} /$ $\mathrm{TiO}_{2}$ and further increase will lead to lower efficiencies. Consequently, the optimum amount for $\mathrm{H}_{2} \mathrm{O}_{2}$ is $12.5 \mathrm{ml}$.

\section{Air Bubbling}

The role of aeration in photocatalytic degradation is inevitable. Dissolved oxygen (DO) increases quantum efficiencies of photocatalytic degradation partly by inhibiting electron-hole recombination. In fact, DO acts as electron acceptor during superoxide radical anion formation, which leads to separate electrons and holes. It has been reported that the reaction of $\mathrm{O}_{2}$ with electrons at the surface of catalyst is slow and it is regarded as the rate- determining step in photocatalysis. Air bubbling is the simplest way to supply molecular oxygen; moreover, it provides turbulence, which assists mass transfer [40, 41]. The effect of aeration on phenol degradation is displayed in Fig. 9. It is observed that after $120 \mathrm{~min}$, When there is no oxidizing agent (no aeration, and no $\mathrm{H}_{2} \mathrm{O}_{2}$ ), phenol degradation is negligible. According to Fig. 9, increasing the aeration flow rate leads to enhance the phenol degradation. As a result, the highest flow rate $(9 \mathrm{l} / \mathrm{min})$ is considered the optimum. Albeit, it is of great importance that compared to $\mathrm{H}_{2} \mathrm{O}_{2}$, aeration is less efficient.

\section{Temperature}

In general, the activation energy of photocatalytic reactions is provided by photons and operations take place at room temperature. To study the influence of temperature, an experiment was performed at 27,37 , and $47{ }^{\circ} \mathrm{C}$. Figure 10 shows the effect of temperature rise on the photodegradation of phenol. It represents that the higher the temperature, the less phenol photodegradation. As it can be seen in Fig. 10 twenty degrees of temperature rise above room temperature drastically drops phenol degradation. In fact, degradation of phenol at $47^{\circ} \mathrm{C}$ is inconsiderable. It could be the result of the decrease in dissolved oxygen at higher temperatures. Presence of oxygen is favorable and it prevents the recombination of $\mathrm{e}^{-}$and $\mathrm{h}^{+}$of the $\mathrm{Fe} / \mathrm{TiO}_{2}$ photocatalyst $[42,43]$. Based on the obtained results, the catalytic degradation of phenol is recommended to be performed at ambient temperature.

\section{Inorganic ions}

The existence of inorganic ions is shown to have a significant effect on the photocatalytic degradation of organic
Fig. 8 The optimization of $\mathrm{H}_{2} \mathrm{O}_{2}$ dosage in the phenol degradation process

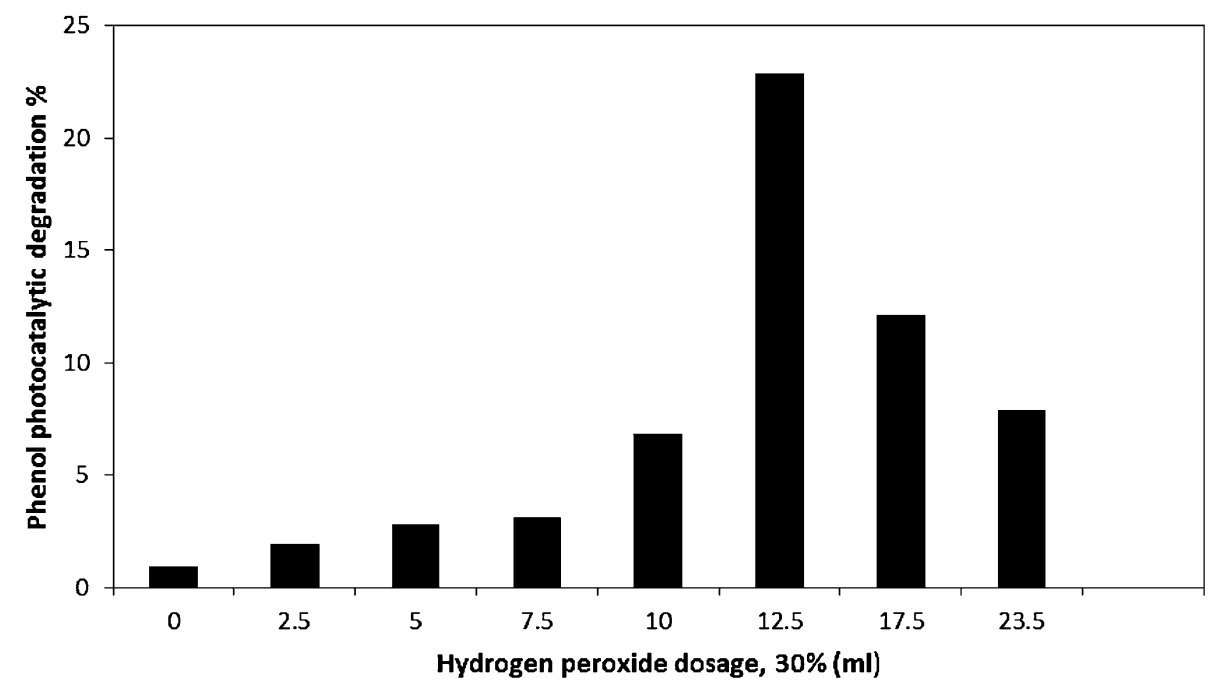


Fig. 9 The effect of aeration on phenol photodegradation

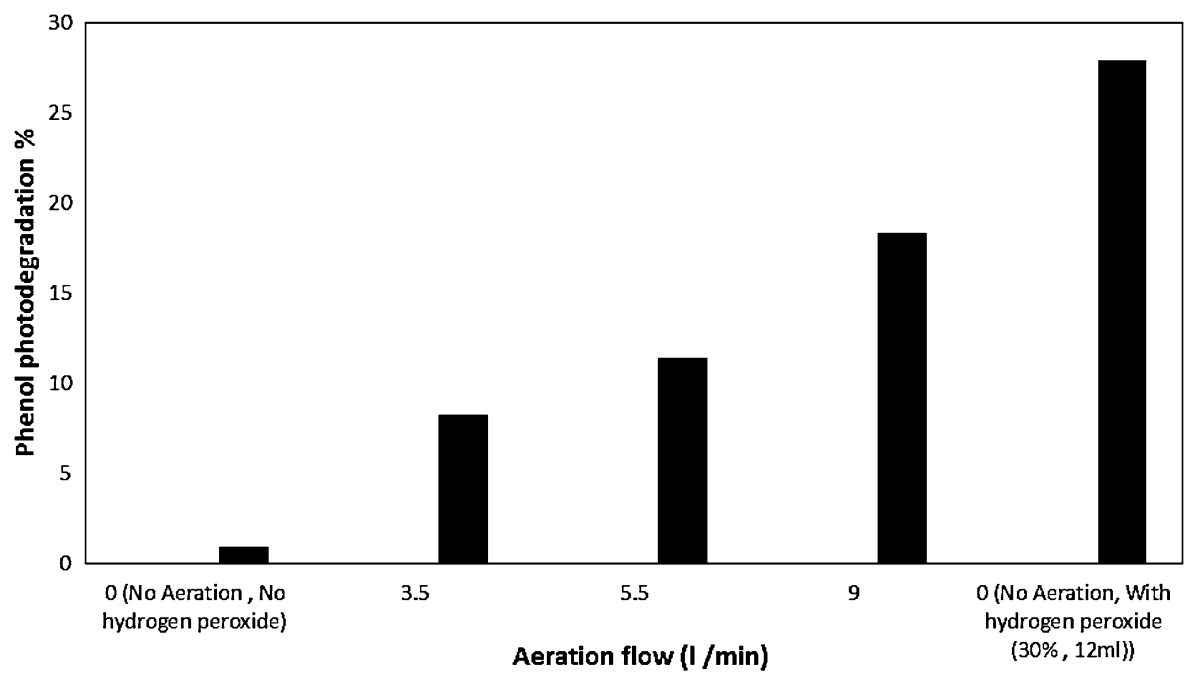

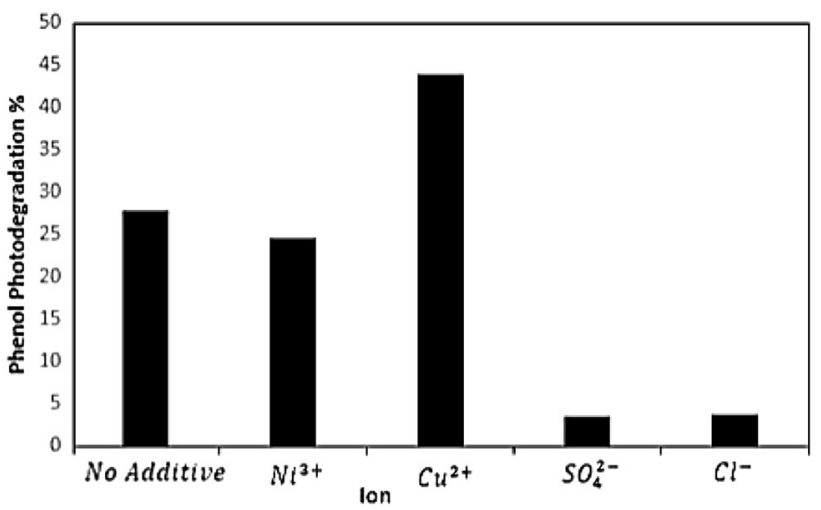

Fig. 10 The effect of temperature on phenol photodegradation

compounds. In this test, the effect of the existence of different inorganic ions including $\mathrm{Ni}^{3+}, \mathrm{Cu}^{2+}, \mathrm{SO}_{4}{ }^{2-}$, and $\mathrm{Cl}^{-}$in the phenol synthetic wastewater was investigated. The concentration of additive ions was the same $(1 \mathrm{mM})$ in each experiment. The results are shown in Fig. 11. Anions and phenol are in a competition to react with $\mathrm{OH}$ radicals, and thus they hinder phenol photodegradation. The low efficiency of the degradation process (less than $5 \%$ ) once $\mathrm{SO}_{4}{ }^{2-}$, and $\mathrm{Cl}^{-}$being added to phenol solution highlights this finding. KASHIF Naeem and Ouyang Feng have enunciated that anions affect the phenol photocatalytic degradation, they reported the inhibition order of the investigated anions as $\mathrm{Cl}^{-}>\mathrm{SO}_{4}{ }^{2-}>\mathrm{NO}_{3}{ }^{-}>\mathrm{CO}_{3}{ }^{2-}$ [44].

Cations absorbing on the surface of iron-modified titanium dioxide are reduced by activated electrons. Therefore, electron and holes will be separated more efficiently and their recombination is avoided. It seems that the existence of cations should have a positive influence on phenol degradation. Figure 11 shows that addition of copper

Fig. 11 The effect of existence of inorganic ions on the phenol photodegradation

enhances the performance of $\mathrm{Fe} / \mathrm{TiO}_{2}$; this arose from electron scavenging effect that inhibits the recombination of the photogenerated electron and holes. Whereas, the addition of $\mathrm{Ni}^{3+}$ slightly diminishes the efficiency of the catalyst, probably due to reaction with phenol and subsequently, the formation of phenol complexes. Accordingly, the influence of inorganic ions was observed to follow this order: $\mathrm{Cu}^{2+}>$ No additive $>\mathrm{Ni}^{3+}>\mathrm{Cl}^{-}>\mathrm{SO}_{4}{ }^{2-}$. Furthermore, it has been shown that the addition of copper as additive ion to phenol solution boosts the degradation of phenol; the highest phenol degradation efficiency after $120 \mathrm{~min}(43.85 \%)$ was attained under this condition. From the observed superior performance of $\mathrm{Fe} / \mathrm{TiO}_{2}$ catalyst once copper ion was added to phenol synthetic wastewater, it can be concluded that the nanoparticles of $\mathrm{Fe} / \mathrm{TiO}_{2}$ will be an extremely capable catalyst for treating industrial wastewaters containing both phenol and heavy metals such as copper. 


\section{Conclusion}

Iron-modified titanium dioxide was successfully synthesized by the sol-gel method. The outstanding results of the characterization of the catalyst are as follows: XPS results show that titanium and oxygen are the main elements, which are present in the surface of the catalyst. XRD results show that there are two peaks corresponding to the iron oxides of $\mathrm{Fe}_{2} \mathrm{O}_{3}$ in addition to the peaks belonging to rutile and anatase phases. This result indicates that iron is incorporated in $\mathrm{TiO}_{2}$ lattice. Chemical composition of the catalyst by XRF declares that the ratio of $\left(\mathrm{Fe}_{2} \mathrm{O}_{3} / \mathrm{TiO}_{2}\right)$ is $0.21 \%$. The aggregated nanoparticles are observable in TEM images. Porosity of the catalyst is indicated in SEM image. BET calculation reveals that specific surface area of the catalyst is $5.1268 \mathrm{~m}^{2} / \mathrm{g}$ and average pore diameter is $13.9838 \mathrm{~nm}$. Once, there is no oxidizing agent phenol degradation is inconsiderable. Experimental tests assert the positive effect of $\mathrm{H}_{2} \mathrm{O}_{2}$ addition and likewise the effect of aeration. The main objective of activity tests was focused upon the comparative evaluation of $\mathrm{H}_{2} \mathrm{O}_{2}$ addition and the application of Air Bubbling. Experimental results specified that the optimum amount for $\mathrm{H}_{2} \mathrm{O}_{2}$ dosage is $12.5 \mathrm{ml}$. It is notable that the effect $\mathrm{H}_{2} \mathrm{O}_{2}$ is more eminent. After $120 \mathrm{~min}$, the degradation of phenol in an aerated reactor with the optimum flow rate was $18.26 \%$, while $27.87 \%$ of phenol was decomposed in a system in the presence of proper amount of $\mathrm{H}_{2} \mathrm{O}_{2}$. Moreover, the existence of anions show inhibitory effect on the degradation of phenol, and the addition of cations such as $\mathrm{Cu}^{2+}$ into phenol solution exhibits a synergetic effect on the performance of the $\mathrm{Fe} /$ $\mathrm{TiO}_{2}$. The temperature rise has adverse influence on the phenol photocatalytic degradation. Accordingly, temperatures higher than room temperature are not recommended.

Acknowledgments The financial support from University of Kurdistan is gratefully acknowledged.

\section{Compliance with ethical standards}

Conflict of interest The authors declare that they have no competing interests.

Open Access This article is distributed under the terms of the Creative Commons Attribution 4.0 International License (http://crea tivecommons.org/licenses/by/4.0/), which permits unrestricted use, distribution, and reproduction in any medium, provided you give appropriate credit to the original author(s) and the source, provide a link to the Creative Commons license, and indicate if changes were made.

\section{References}

1. Watts, J.F., Wolstenholme, J.: An Introduction to Surface Analysis by XPS and AES. Copyright (C) 2003 by John Wiley \& Sons
Ltd, the Atrium, Southern Gate, Chichester, West Sussex PO19 8SQ, England

2. Zhang, Q., Xu, L., Ning, P., Gu, J., Guan, Q.: Surface characterization studies of $\mathrm{CuO}-\mathrm{CeO}_{2}-\mathrm{ZrO}_{2}$ catalysts for selective catalytic reduction of $\mathrm{NO}$ with $\mathrm{NH}_{3}$. Appl. Surf. Sci. 317, 955-961 (2014)

3. Lorret, O., Francova, D., Waldner, G., Stelzer, N.: W-doped titania nanoparticles for UV and visible-light photocatalytic reactions. Appl. Catal. B Environ. 91, 39-46 (2009)

4. Lee, S.-Y., Park, S.-J.: $\mathrm{TiO}_{2}$ photocatalyst for water treatment applications. J. Ind. Eng. Chem. 19, 1761-1769 (2013)

5. Karimi, L., Zohoori, S.: Superior photocatalytic degradation of azo dyes in aqueous solutions using $\mathrm{TiO} 2 / \mathrm{SrTiO} 3$ nanocomposite. J. Nanostruct. Chem. 3, 3-32 (2013)

6. Park, H., Park, Y., Kim, W., Choi, W.: Surface modification of $\mathrm{TiO}_{2}$ photocatalyst for environmental applications. J. Photochem. Photobiol. C 15, 1-20 (2013)

7. Sun, B., Vorontsov, A.V., Smirniotis, P.G.: Role of platinum deposited on $\mathrm{TiO}_{2}$ in phenol photocatalytic oxidation. Langmuir 19, 3151-3156 (2003)

8. Fu, P., Zhang, P., Li, J.: Photocatalytic degradation of low concentration formaldehyde and simultaneous elimination of ozone byproduct using palladium modified $\mathrm{TiO}_{2}$ films under $\mathrm{UV}_{254+185 \mathrm{~nm}}$ irradiation. Appl. Catal. B Environ. 105, 220-228 (2011)

9. Thomas, J., Yoon, M.: Facile synthesis of pure $\mathrm{TiO}_{2}(\mathrm{~B})$ nanofibers doped with gold nanoparticles and solar photocatalytic activities. Appl. Catal. B Environ. 111-112, 502-508 (2012)

10. Krejcíkovà, S., Matejovà, L., Kocí, K., Obalovà, L., Matej, Z., Capek, L., Šolcovà, O.: Preparation and characterization of Agdoped crystalline titania for photocatalysis applications. Appl. Catal. B Environ. 111-112, 119-125 (2012)

11. Wang, C.M., Heller, A., Gerischer, H.: Palladium catalysis of $\mathrm{O}_{2}$ reduction by electrons accumulated on $\mathrm{TiO}_{2}$ particles during photoassisted oxidation of organic compounds. J. Am. Chem. Soc. 114, 5230-5234 (1992)

12. Yao, Y., Ohko, Y., Sekiguchi, Y., Fujishima, A., Kubota, Y.: Self-sterilization using silicone catheters coated with $\mathrm{Ag}$ and $\mathrm{TiO}_{2}$ nanocomposite thin film. J. Biomed. Mater. Res. A 85B, 453-460 (2008)

13. Wu, D., You, H., Jin, D., Li, X.: Enhanced inactivation of Escherichia coli with Ag-coated $\mathrm{TiO}_{2}$ thin film under UV-C irradiation. J. Photochem. Photobiol. A 217, 177-183 (2011)

14. Yu, J., Xiong, J., Cheng, B., Liu, S.: Fabrication and characterization of $\mathrm{Ag}-\mathrm{TiO}_{2}$ multiphase nanocomposite thin films with enhanced photocatalytic activity. Appl. Catal. B Environ. 60, 211-221 (2005)

15. Angelis, F.D., Fantacci, S., Selloni, A., Nazeeruddin, M.K., Gratzel, M., Amer, J.: Time-dependent density functional theory investigations on the excited states of $\mathrm{Ru}(\mathrm{II})$-dye-sensitized $\mathrm{TiO}_{2}$ nanoparticles: the role of sensitizer protonation. Chem. Soc. 129, 14156-14157 (2007)

16. Morikawa, T., Ohwaki, T., Suzuki, K., Moribe, S., Kubota, S.T.: Visible-light-induced photocatalytic oxidation of carboxylic acids and aldehydes over $\mathrm{N}$-doped $\mathrm{TiO}_{2}$ loaded with $\mathrm{Fe}, \mathrm{Cu}$ or Pt. Appl. Catal. B Environ. 83, 56-62 (2008)

17. Kay, A., Cesar, I., Gratzel, M.: New benchmark for water photooxidation by nanostructured $\alpha-\mathrm{Fe}_{2} \mathrm{O}_{3}$ films. J. Am. Chem. Soc. 128, 15714-15721 (2006)

18. Sun, Q., Leng, W., Li, Z., Xu, Y.: Effect of surface $\mathrm{Fe}_{2} \mathrm{O}_{3}$ clusters on the photocatalytic activity of $\mathrm{TiO}_{2}$ for phenol degradation in water. J. Hazard. Mater. 229, 224-232 (2012)

19. Zhang, Y., Li, Q.: Synthesis and characterization of Fe-doped $\mathrm{TiO}_{2}$ films by electrophoretic method and its photocatalytic activity toward methyl orange. Solid State Sci. 16, 16-20 (2013)

20. Palanisamy, B., Babu, C.M., Sundaravel, B., Anandan, S., Murugesan, V.: Sol-gel synthesis of mesoporous mixed $\mathrm{Fe}_{2} \mathrm{O}_{3}$ / 
$\mathrm{TiO}_{2}$ photocatalyst: application for degradation of 4-chlorophenol. J. Hazard. Mater. 252-253, 233-242 (2013)

21. Ni, M., Leung, M.K.H., Leung, D.Y.C., Sumathy, K.: A review, and recent developments in photocatalytic water-splitting using $\mathrm{TiO}_{2}$ for hydrogen production. Renew. Sustain. Energy Rev. 11, 401-425 (2007)

22. Iliev, V., Tomova, D., Rakovsky, S.: Nanosized N-doped $\mathrm{TiO}_{2}$, and gold modified semiconductors-photocatalysts for combined UV-visible light destruction of oxalic acid in aqueous solution. Desalination 260, 101-106 (2010)

23. Oganisian, K., Hreniak, A., Sikora, A., Gaworska-Koniarek, D., Iwan, A.: Synthesis of iron doped titanium dioxide by sol-gel method for magnetic applications. Process. Appl. Ceram. 9, 43-51 (2015)

24. Hreniak, A., Gryzło, K., Boharewicz, B., Sikora, A., Chmielowiec, J., Iwan, A.: Preparation and optical properties of ironmodified titanium dioxide obtained by sol-gel method. Opt. Mater. 46, 45-51 (2015)

25. Ranjit, K., Viswanathan, B.: Synthesis, characterization and photocatalytic properties of iron-doped $\mathrm{TiO} 2$ catalysts. J. Photochem. Photobiol. A Chem. 108, 79-84 (1997)

26. Liu, Y., Wei, J.H., Xiong, R., Pan, C.X., Shi, J.: Enhanced visible light photocatalytic properties of $\mathrm{Fe}$-doped $\mathrm{TiO} 2$ nanorod clusters and monodispersed nanoparticles. Appl. Surf. Sci. 257, 8121-8126 (2011)

27. Naik, B., Parida, K.M.: Solar light active photodegradation of phenol over a $\mathrm{Fe}_{\mathrm{x}} \mathrm{Ti}_{1-\mathrm{x}} \mathrm{O}_{2-\mathrm{y}} \mathrm{N}_{\mathrm{y}}$ nanophotocatalyst. Ind. Eng. Chem. Res. 49, 8339-8346 (2010)

28. Barakata, N.A.M., Taha, A., Motlak, M., Nassar, M.M., Mahmoud, M.S., Al-Deyab, S.S., El-Newehyd, M., Kim, H.Y.: ZnO $\& \mathrm{Fe} 2 \mathrm{O} 3$-incoportaed $\mathrm{TiO} 2$ nanofibers as super effective photocatalyst for water splitting under visible light radiation. Appl. Catal. A Gen. 481, 19-26 (2014)

29. Schicks, J., Neumann, D., Specht, U., Veser, G.: Nanoengineered catalysts for high-temperature methane partial oxidation. Catal. Today 81, 287-296 (2003)

30. De Biasi, R.S., Grillo, M.L.N.: ESR investigation of $\mathrm{Fe}^{3+}$ diffusion in rutile. J. Phys. Chem. Solids 57, 137-138 (1996)

31. Zhu, Jiefang, Chen, Feng, Zhang, Jinlong: $\mathrm{Fe}^{3+}-\mathrm{TiO}_{2}$ photocatalysts prepared by combining sol-gel method with hydrothermal treatment and their characterization. J. Photochem. Photobiol. A 180, 196-204 (2006)

32. Egerton, T.A., Harris, E., Lawson, E.J., Mile, B., Rowlands, C.C.: An EPR study of diffusion of chromium into rutile. Phys. Chem. Chem. Phys. 2, 3275-3281 (2000)
33. Wanger, C.D., Riggs, W.M., Davis, L.E., Moudler, J.F.: Handbook of X-ray Photoelectron Spectroscopy. Eden Prairie, Minnesota (1979)

34. Pang, Y.L., Abdullah, A.Z.: Effect of low $\mathrm{Fe}^{3+}$ doping on characteristics, sonocatalytic activity and reusability of $\mathrm{TiO}_{2}$ nanotubes catalysts for removal of Rhodamine B from water. J. Hazard. Mater. 235-236, 326-335 (2012)

35. Yuan, R., Zhou, B., Hua, D., Shi, C.: Enhanced photocatalytic degradation of humic acids using $\mathrm{Al}$ and $\mathrm{Fe}$ co-doped $\mathrm{TiO}_{2}$ nanotubes under UV/ozonation for drinking water purification. J. Hazard. Mater. 262, 527-538 (2013)

36. Leofanti, G., Padovan, M., Tozzola, G., Venturelli, B.: Surface area and pore texture of catalysts. Catal. Today 41, 207-219 (1998)

37. Mesgari, Z., Gharagozloub, M., Khosravi, A., Gharanjig, K.: Synthesis, characterization and evaluation of efficiency of new hybrid $\mathrm{Pc} / \mathrm{Fe}-\mathrm{TiO} 2$ nanocomposite as photocatalyst for decolorization of methyl orange using visible light irradiation. Appl. Catal. A Gen. 411-412, 139-145 (2012)

38. Akhlaghian, F., Sohrabi, S.: $\mathrm{Fe} / \mathrm{TiO}_{2}$ catalyst for photodegradation of phenol in water. Int. J. Eng. (IJE) Trans. A Basics 28, 499-506 (2015)

39. Luenloi, T., Chalermsinsuwan, B., Sreethawong, T., Hinchiranan, N.: Photodegradation of phenol catalyzed by $\mathrm{TiO} 2$ coated on acrylic sheets: kinetics and factorial design analysis. Desalination 274, 192-199 (2011)

40. Youn, N.K., Heo, J.E., Joo, O.S., Lee, H., Kim, J., Min, B.K.: The effect of dissolved oxygen on the 1,4-dioxane degradation with $\mathrm{TiO}_{2}$ and $\mathrm{Au}-\mathrm{TiO}_{2}$ photocatalysts. J. Hazard. Mater. 177, 216-221 (2010)

41. Ling, C.M., Mohamad, A.R., Bhatia, S.: Performance of photocatalytic reactors using immobilized $\mathrm{TiO}_{2}$ film for the degradation of phenol and methylene blue dye present in water stream. Chemosphere 57, 547-554 (2004)

42. Nezamzadeh-Ejhieh, A., Salimi, Z.: Heterogeneous photodegradation catalysis of o-phenylenediamine using $\mathrm{CuO} / \mathrm{X}$ zeolite. Appl. Catal. A Gen. 390, 110-118 (2010)

43. Ahmed, S., Rasul, M.G., Martens, W.N., Brown, R., Hashib, M.A.: Heterogeneous photocatalytic degradation of phenols in wastewater: a review on current status and developments. Desalination 261, 3-18 (2010)

44. Kashif, N., Ouyang, F.: Parameters effect on heterogeneous photocatalysed degradation of phenol in aqueous dispersion of $\mathrm{TiO}_{2}$. J. Environ. Sci. 21, 527-533 (2009) 